\title{
Supernumenary Teat in West Africa Dwarf Goat in Ibadan, Southwest Nigeria
}

\author{
Kabir Ayobami Raheem ${ }^{1}$ and Olufisayo Oluwadamilare Leigh ${ }^{2}$ \\ ${ }^{1}$ Dept. of Vet. Surgery and Theriogenology, Michael Okpara University of Agriculture, Umudike, Nigeria \\ ${ }^{2}$ Dept. of Vet. Surgery and Reproduction, University of Ibadan, Ibadan, Nigeria
}

\begin{abstract}
Supernumenary teat is a congenital condition of ancillary teats in addition to the primary teats. In this study, we report for the first time the incidence of supernumerary teat in West African Goat in Ibadan, Southwest Nigeria. There was $17 \%$ incidence of supernumerary teat in a flock of 18 WAD goats meant for a particular research work. The goats were source from different areas of Ibadan metropolis without observing for breeding soundness examination or considering the mammary gland before purchase. The condition was noted during ultrasound presentation of the doe for pregnancy evaluation. Goat with supernumerary can be bred successfully and contra-indication occurs when the goat has triplet as the third kid may be holding on to this non-functional teat. Supernumenary teat is of particular importance in dairy stock where it predisposes to mastitis as the unused teat serve as a good route for pathogens. It may also reduce milking efficiency as it constitutes hindrance to fitting of the milking machine to the udder. On the contrary, supernumenary teat may be useful for teat grafting to restore teat anatomy during an acute damage to primary teat tip. In this report, none of the kids from these goats exhibited supernumenary teat, in spite of the heritable nature of this condition. Further studies involving large stock in the study area are suggested. In conclusion, this report has emphasized the need for breeding soundness examination including mammary gland to identify and eliminate supernumenary teat during purchase of goat for research purpose especially in study that has to do with reproduction.
\end{abstract}

Keyword: Supernumenary teat, mammary gland, milk, goat.

\section{Introduction}

Mammalian neonate relies exclusively on colostrum and then milk for survival during the first few days after birth. Apart from supplying all the essential nutrients required by the neonate during early life, the colostrum also provides immunity through immunoglobulin and hence very essential for neonatal survival [1]. This is more evident especially in ruminant, where the epitheliochorial form of placentation interferes with foetal acquisition of passive immunity in utero. The primary site of milk synthesis is the alveoli of the mammary gland. The synthesized milk is temporarily stored in the gland cistern, while the teat through its orifice served as a route for removal of the milk when the teat is suckled by the neonate [2].

There are two primary teats in goat and four in cow. Therefore, additional teat in excess of this number is known as supernumenary teat or hyperthelia. Supernumenary teat (SNT) is a congenital condition associated with combination of some genes with incidence as high as $100 \%$ in recessive homozygous genes [3]. The main teat, being bigger and conspicuous is quite distinguishable from the SNT. The primary teat is a functional teat with orifice(s) that connects to the gland cistern. SNT are of various types. Ancillary teats consist of more than the normal number of teat in each half of the udder. A fish or fork teat is a single teat that flattens but splits near the end thereby possessing two separate orifices. Split teat is a single teat that splits in to two separates orifices. The double-orifice teat has more than one orifice per teat. Usually when ancillary teat is present, the major teat is more conspicuously bigger and easily differentiated from the other SNT. Physiologically, the SNT usually has no duct that connects to the primary mammary gland. In that case, it is vestigial and non-functional. In some other cases, it may be connected to small glands or even the main glands, in which case, it yields but small amount of milk compared to the primary or main teat when suckled[4].

In the present study, we reported the incidence of SNT in West African Dwarf goat in Ibadan, Southwestern, Nigeria. The possible causes, treatment and reproductive implication of this condition are the subject matter of this article.

\section{History And Diagnosis}

The animals are sourced from the different areas of Ibadan, namely Samonda, Abadina and Bodija. Eighteen West Africa Dwarf (WAD) female goats were acquired and their ages ranged between 8 months to 3 years at the point of purchase according to dentition. The shape of the udder was never considered at the time of buying the animals. However, the supernumerary feature was recognized at the time of pregnancy evaluation 


\section{Results}

3 goats out of the 18 goats (17\%) in this study exhibited one form of SNT or the other. The first goat had a fish or fork teat attached to the left primary teat (Figure 1). The second had a SNT in each of the right and the left teat (Figure 2). These are smaller and were about $0.2 \mathrm{~cm}$ cranial to the main teat. The third goat had teat similar to the latter except that the teats were further $(1.6 \mathrm{~cm})$ from the primary teats (Figure 3). There was an equidistant between the primary and the ancillary teat of the left and the right. On digital application of pressure on the mammary gland, milk was oozing out only from the primary teat while the SNT was non-patent. This indicates that the SNT lacked orifice or did not connect to the gland cistern. At parturition, the goats had one kid each, 2 female and I male while none of the two female kids exhibited SNT.

\section{Discussion}

To the best of our knowledge, this report of SNT in WAD goat in Ibadan, Southwestern Nigeria constitutes the first of its kind in this species in the study area. This proportion is higher than $11 \%$ reported in Red Sokoto goat in Kano, Northern Nigeria [5] and similar to $15 \%$ incidence reported in WAD goat [6]. The prevalence of SNT in this study is also lower than $27 \%$ observed in a stock of 131 goats in Brazil [7], showing that the incidence is not an unusual occurrence in goat. Reports of similar condition in human [8], and other species such as cattle [9] Sheep [10,11] and mice [12] are found in the literature. In contrary to cow with majority (88\%) of the extra teats being caudal as was reported by St'avikova et al. [14], all the extra teats in this study were located cranially to the primary teat.

Anatomically, the udder is divided into 2 cavities, the right and the left in goat and sheep, and four in cow. The milk is formed from the maternal blood in the alveoli within the mammary lobes (Figure 4), from where they are transported via lactiferous duct to the gland cistern. The latter serves as a temporary reservoir before milk-let-down stimulates milk removal through the teat orifice. Although, goat with SNT can be bred successfully, this defect is contra-indicated when the doe has triplet and the third kid has to hook on to this nonfunctional teat while the other two have held on to each of the two primary teat.

SNT as a congenital anomaly is of particular importance in dairy cattle because it may predispose the cow to mastitis since the extra unused opening serves as a good route for pathogens. It may also inhibit proficient milking by interfering with attachment of milking apparatus. Diagnosis of SNT is done by examination at a routine time within the first 8 month of life especially during vaccination. If confusion arise as to which is the true teat, the heifer should be allowed to grow for more months. The treatment of choice is surgical removal of the teat as early as 3 to 4 months of age [3]. This time the surgery is simpler and may involve only cutting off the teat whether the ancillary teat has a separate gland or not. If the animal is left to attain puberty and has begun lactation, the surgery then becomes complex because of the need to suture the glands. On the other hand, SNT may be useful for teat grafting to restore teat anatomy during an acute damage to the primary teat tip [14]. In a recent study, it was revealed that SNT removal is not necessary in dairy sheep as there was no significant difference in milk yield in sheep with four and two teats [10].

Surgery was not done in the present study because it was not considered to be worthwhile since the animals were not intended for dairy. Rather, the animals were allowed to kid. To avoid breeding any longer, the three goats were sold for meat. Fortunately, SNT was not observed in any of the two female kids. Further studies involving more animals in the study area are suggested.

\section{Figures}

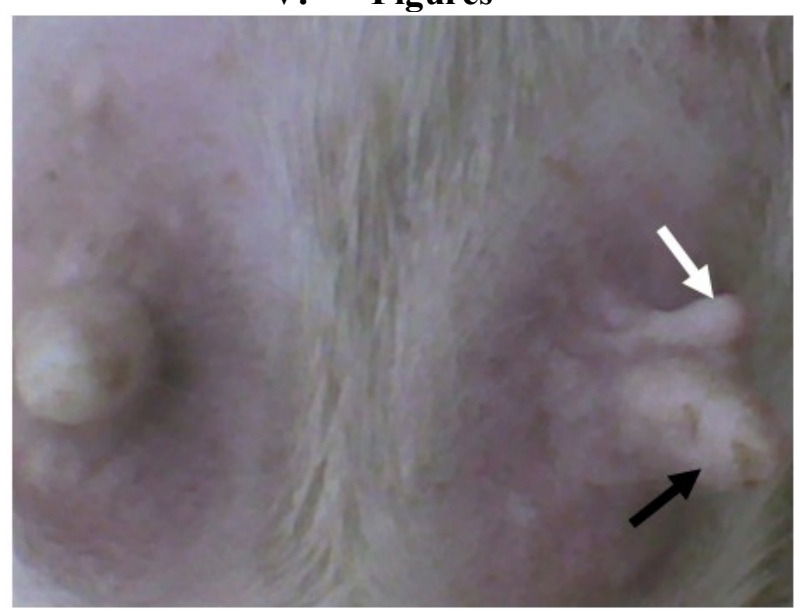

Figure $1 \mathrm{~A}$ fish or forked teat (white arrow) on the left primary teat (black arrow). 


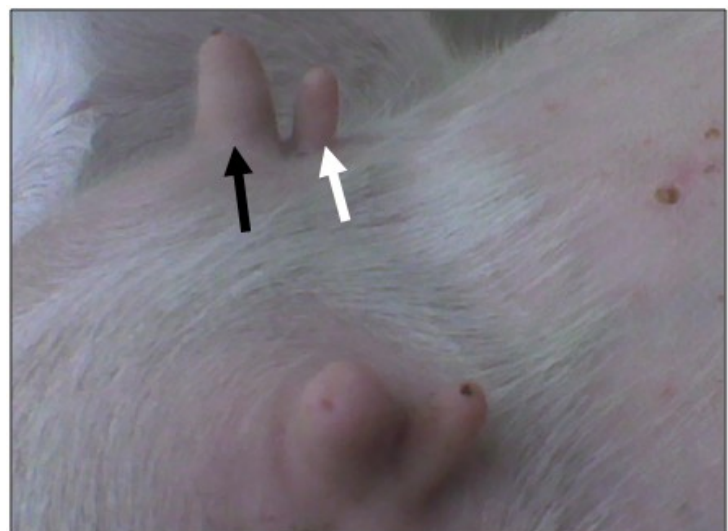

Figure 2 Ancillary teats (white arrow) in pregnant doe, located cranially to the primary teats (black arrow).

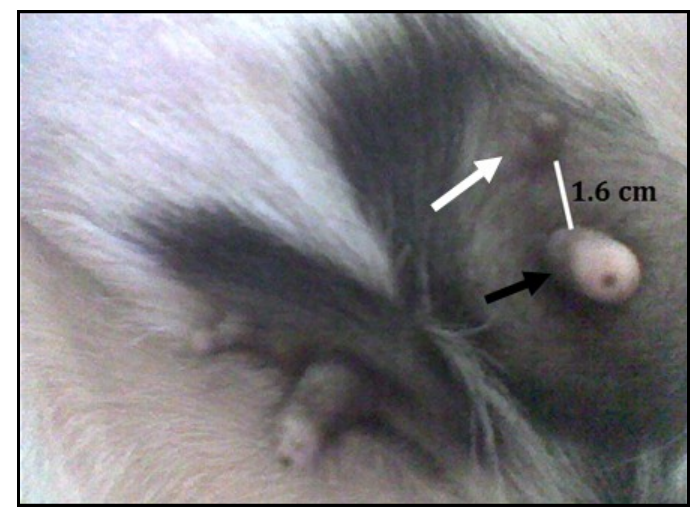

Figure 3 Ancillary teats (white arrow) located cranially to the primary teats (black arrow) in WAD goat at a distance of $1.6 \mathrm{~cm}$ from the primary teat.

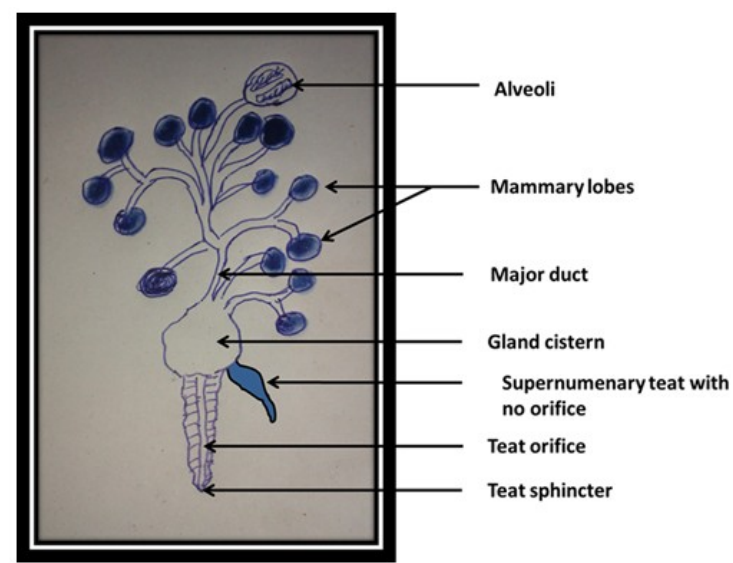

Figure 4 Schematic illustration of the mammary gland showing the true teat with the gland cistern and ancillary teat that has no teat orifice

\section{Conclusion}

In this study, we have reported an incidence of SNT in goat in Ibadan, Southwest Nigeria and discussed its reproductive implication. The results have emphasized the essence of examination of the udder for presence of SNT during breeding soundness examination at the time of purchase of female animal for research of reproductive inclination. However, none of the kids from these animals in the present study had SNT, in spite of the heredity of this condition. Female animals exhibiting SNT are considered unsuitable for breeding to avoid propagating the trait. 


\section{References}

[1]. Larson, B. L., H. L. Heary Jr., and J. E. Devery, Immunoglobulin production and transport by the mammary gland. Journal of Dairy Science, 63, 1980, 665-671.

[2]. Senger P.L., Pathways to pregnancy and parturition (Pullman, WA: Current Conceptions, 2005).

[3]. M. Brka, Reinsch, N. and E. Kalm, Determination of the inheritance pattern of hyperthelia in cattle by maximum likelihood analysis.Journal of Animal Breeding and Genetics, 117, 2000, 425-431

[4]. J. Thomas, Divers, Simon Peek, Thomas J. Divers and Simon Peek, Rebhun's Diseases of Dairy Cattle (Missouri, US: Saunders Elsevier, 2008).

[5]. S. Oseni, Sonaiya, B., Omitogun, G., Ajayi, A and I. Muritala, West African Dwarf goat production under village conditions: 1. Characterisation and the establishment of breed standards, Conference on International Agricultural Research for Development University of Bonn, Germany, 2006, 1-5

[6]. G. N. Akpa, C.Alphonsus, S.Y. Dalha and Y.Garba, Herd structure and incidence of supernumerary teats in smallholder goat production in Kano State, Continental Journal of Veterinary Sciences 4, 2010, 9 -15.

[7]. T.M.M Machado., J.U.Alvesand F.R. Silva,Arquivos de CiênciasVeterinárias e Zoologia da Unipar 5, 2002, $219-224$

[8]. C. E. Urbaniand R.Betti, Accessory Mammary Tissue in Clinical Practice (McGraw-Hill Libri Italia srl, Piazza Emilia, Milano, Italy, 1996).

[9]. M. Brka, N. Reinsch, and E. Kalm, Is there linkage between supernumerary teats in cattle and BTA3 markers? Arch. Tierz., Dummerstorf 45 (5), 2002, 429-432

[10]. C. Palacios and J.A. Abecia, Supernumerary teat removal can be avoided in dairy sheep. Journal of Applied Animal Welfare Science, 17(2), 2014, 178-82

[11]. Vainikainen, V. On the heritability of supernumerary nipples in Finnish home-bred sheep. Maataloustieteellinenaikakauskirja, 17, 1945, 11-18

[12]. B. A. Howard and B. A. Gusterson, The characterisation of a mouse mutant that displays abnormal mammary gland development. Mammalian Genome, 11,2000, 234-237

[13]. M. St'avikova, L. Lojda and J. Polacek, Heredity of the position of rudimentary teats in cows of the Czech Spotted breed. Veterinary Medicine (Praha), 25, 1980,129-137.

[14]. S.Saifzadeh, Hobbenaghi, R. and J. Farid, Teat tip reconstruction by supernumerary teat autotransplantation in cattle. Veterinary Surgeon,34(4), 2005,366-71. 